\title{
Calibration and Validation of a Continuum Damage Mechanics Model in Aid of Axial Crush Simulation of Braided Composite Tubes
}

\author{
Carla McGregor ${ }^{\mathrm{a}}$, Navid Zobeirya ${ }^{\mathrm{a}}$, Reza Vaziria ${ }^{*}$, Anoush Poursartip ${ }^{\mathrm{a}}$ and Xinran Xiao ${ }^{\mathrm{b}}$
}

\begin{abstract}
We present the details of a combined experimental and numerical study used to calibrate the parameters of a macro-mechanical damage model that is incorporated as a user material model in the explicit finite element program, LS-DYNA, to represent the progressive damage behaviour of composites at the level of the representative volume element. Specifically, the model parameters defining the transverse tensile and axial compressive response of a triaxially-braided carbon fibre/epoxy composite are determined based on results from notched tensile, 4-point bend and eccentric compression tests. To demonstrate the validity of the material model and its calibrated input parameters, the response of notched tensile coupon and eccentric compression tests are simulated and shown to correlate well with experimental measurements. Further validation of the model is provided here and in Ref. [1] through successful simulation of the axial crushing of square tubes made of the same material.
\end{abstract}

Keywords: Braided Composite Tubes; Progressive Crushing; Model Calibration; Finite Element Analysis (FEA); Damage Mechanics; Fracture Tests

\section{Introduction}

Composite tubes for energy absorption have received considerable amount of attention in the past few decades due to their high specific properties with the potential for weight savings in aerospace and automotive applications. One of the biggest obstacles to the successful integration of these components into mainstream automotive products is the inability to confidently predict their performance using finite element analyses; nowadays a standard design step for automotive metallic components. 
Given the complex nature of damage formation and failure in laminated composites, especially under dynamic loads (e.g. low and high velocity impact, and crush loading events), simulation of the damage response of composite components poses a major challenge to structural analysts. At the laminate level, the interactions of various failure modes including intra-laminar failure (fibre and matrix failure) and interlaminar failure (delamination), adds to the complexity of the problem. The complexity is highlighted further considering that the initiation and propagation of discrete damage modes such as delamination and splitting are highly geometry and lay-up dependent (e.g. [2] and [3]). In recent years, many studies have focussed on development of damage models that are capable of addressing these challenges. Ranging from discrete models to continuum damage models, they vary in terms of underlying assumptions for damage evolution, computational efficiency, associated characterization/calibration efforts, and applicability [4]. Currently, the ply-based approaches are notably popular (e.g. [5]-[8]). In such approaches, usually, the behaviour of individual plies is simulated separately using continuum (smeared) damage-based models (e.g. [9],[10]). The interaction of plies and the formation of inter-laminar failure modes, on the other hand, are simulated using discrete models such as those based on cohesive zone methods. Unidirectional or woven plies which are the repeating units of the laminate in these approaches, have to be experimentally characterized. Inter-laminar properties are characterized separately using standard tests.

Considering the complex reinforcement architecture of braided composites, many studies have focused on multi-scale approaches to simulate the progressive failure response of these composites. Micromechanics based approaches, for example, have been used to predict the nonlinear failure response of braided composites (e.g. [11]-[14]). To include the effect of braided architecture at larger scales, meso-scale approaches based on unit cell discretization (i.e. sub-cell approach) have been widely used for progressive damage modelling of braided composites ([15]-[19]). A meso-scale simulation approach was implemented by Zhang et al ([20]-[22]) for progressive tensile failure modelling and to evaluate the free edge effects in straight-sided coupons. In recent years, attention has been paid to the effect of manufacturing defects on the failure response of braided composites [23]. Borowski et al [24] employed a multi-scale simulation approach of the response of braided composites from micro-level to macro-level while considering the effect of manufacturing-induced defects due to the mismatch of free strains and thermal properties. The wide range of proposed simulation approaches for braided composites underscores the challenges 
associated with simulating the failure behaviour of these multi-scale materials. Considering the higher propensity for development of manufacturing-induced defects in braided composites compared to unidirectional composites, predicting the performance of braided composites under static and dynamic loads becomes a formidable task.

To avoid the difficulties associated with characterization and simulation of braided composites with a high degree of manufacturing defects (i.e. poor quality braided composites), in this paper, a ply-based modelling approach is employed to simulate crushing of braided composites. However, unlike ply-based models for which unidirectional/woven layers constitute the repeating units, for braided composites, a braided layer with fibres oriented in multiple directions (e.g. $[0 / \pm 45]$ considered in this study) forms the repeating unit. A simplified continuum damage mechanics (CDM) based model, CODAM (for COmposite DAMage) is employed to represent the damage behaviour of braided layers. The model uses a macro-mechanical strainsoftening (stress-strain curve with a descending branch after the peak stress) approach to represent, in a smeared fashion, the effect of the constituent damage growth on the overall response of a macro-level representative volume of the material. Such an approach is intended to capture the essence, rather than the details, of the damage progression in the material leading to its nonlinear behaviour up to failure.

Representing fracture in a smeared manner by reducing the material stiffness and strength after the peak strength of the material has been reached is relatively easy to implement in finite element codes and therefore, the continuum based smeared cracking approach is a commonly adopted methodology for practical computational analysis of large-scale composite structures.

In braided composite tubes (Fig. 1), material fracture and delamination is estimated to account for the majority of the total energy absorbed, with the remaining energy absorbed through friction and heat generation [25]. It is imperative, therefore, to accurately characterize the material behaviour for finite element representation of the problem. Typically, material model parameters are determined from standard mechanical testing. However, the step from mechanical testing to material model calibration is difficult for a number of reasons. Composites, and braided composites in particular (due to their coarse architecture), are very sensitive to edge effects ([26]- [30]). These edge effects can trigger failure mechanisms in the coupon specimen that are not representative of failure in the structure (i.e. tow pull-out versus tow fracture) leading to erroneous input parameters. It has been shown that edge effects affect the failure response of 
braided composites (e.g. [26]). The influence of edge effects on accurate measurement of elastic properties has also been quantified [21]. To overcome difficulties associated with characterizing braided composites using standard specimens, and to minimize the edge effects, notched coupon tests and tubular geometries of specimens have been proposed in the literature ([27] and [28]). Kohlman and co-workers ([26] and [27]), for example, developed a double edge-notched (DEN) coupon testing approach to evaluate the tensile strength of braided composites.

It is also important to represent the consequences of substantial levels of damage growth in the material. Characterization of this damage growth, which in itself is complex, involving many competing mechanisms such as matrix cracking, fibre breakage, fibre kinking and delamination, often requires specialized testing that promote stable damage progression in contrast to catastrophic failure. Given these difficulties, extreme care should be taken in determining phenomenological model parameters to ensure that they are accurate and that they capture the true behaviour of the material.

In this paper, the material model parameters that define the damage behaviour for each braided layer are obtained from a combination of standard coupon, notched tensile fracture, 4-point bend, and eccentric compression tests. In order to minimize edge effects, a notched specimen geometry based on the overheight compact tension test configuration is used to further evaluate both the elastic and fracture properties. In the absence of reliable test data for stiffness and strength, normally arising from standard coupon tests, the successful simulation of the notched coupon test is used as a basis for numerical adjustments of tensile stiffness and strength values in the transverse direction. The 4-point bend tests are used to estimate an average value for the axial compressive strength and simulation of eccentric compression tests are then used as a means of validating the calibrated compressive model. The delamination properties consisting of maximum value of inter-laminar traction for onset of delamination and interface toughness (area under the interface traction-separation curve) for progression of delamination are estimated from Double Cantilever Beam (DCB) tests. The final validation of the model is provided here, and in Ref. [1], through successful simulation of the axial crushing of square-section tubular structures made of the same braided material.

\section{Braided Composite Material}

The energy absorption and mechanical properties of two-dimensional, 2-ply and 4-ply, carbon fibre triaxially-braided composites were investigated. The braid structure consisted of Fortafil 80k axial tows 
(an $80 \mathrm{k}$ tow is composed of 80,000 individual fibres) and Grafil $12 \mathrm{k}$ biaxial tows arranged in a [0/ \pm 45$]$ pattern (Fig. 1) in a vinyl-ester epoxy (Ashland Hetron 922) resin. All the braided panels used for in-house testing were supplied by General Motors Corporation. These panels were fabricated by Excel Pattern Works, Inc (Dearborn, MI) by pouring the resin into a mould containing the braid. Mould pressure was maintained at 650 to $690 \mathrm{kPa}$ (90 to $100 \mathrm{psi}$ ) and a temperature of $66^{\circ} \mathrm{C}\left(150^{\circ} \mathrm{F}\right)$ was applied to one side of the mould. The plaque was then post-cured at a temperature of $93{ }^{\circ} \mathrm{C}\left(200{ }^{\circ} \mathrm{F}\right)$ for 1 hour. The quality of the material was fair, with a moderate number of voids, resin rich areas, and variable braid pattern. The thickness of specimens cut from these panels was observed to vary by up to $5 \%$, with average values of 2.3 and $6.1 \mathrm{~mm}$, for the 2-ply and 4-ply braid, respectively.

\section{Overview of Constitutive Model}

\subsection{Modelling approach}

As mentioned previously, for finite element modelling of the axial crushing behaviour of these braided composite tubes, the material response of each layer was modelled using a continuum damage mechanics (CDM) based model for composite materials. CDM models represent the mechanics of distributed cracking, lending them well to modelling composite damage growth. In essence, CDM approaches attempt to represent the effect of progressive damage growth at the micro-scale level by appropriate deterioration of the material properties at the macro-scale level. Delamination is simulated using a tie-break contact between the braided layers that obeys a traction-separation cohesive law.

\subsection{CODAM}

CODAM [31], is implemented as a user material model into the explicit finite element analysis program, LS-DYNA. It represents the effect of progressive damage growth at the macro-scale level of the Representative Volume Element (RVE). The RVE response represents the damage behaviour within the fracture process zone (FPZ) if the material is tested under conditions that lead to stable damage growth.

Damage growth in the RVE is tracked by a damage parameter $(\omega)$, which ranges from a value of 0 , indicating no damage to a value of 1 , indicating complete damage. At the simplest level, the damage parameter is defined as a linear function of the RVE strain, and this is in turn manifested by a linear reduction in the RVE modulus. The RVE therefore exhibits a strain-softening behaviour. Fig. 2 shows a 
general strain-softening response, in which the material is initially elastic until damage initiates (A-B), after which the modulus degrades and the stresses drop (B-C). This stress-strain response can also be thought of as a stress-displacement (or traction-separation) response defined for the specific characteristic damage height (i.e. the height over which damage is fully developed in the FPZ). Also shown in the figure is the assumed linear damage growth law and an example of the characteristic damage height observed in a carbon fibre/epoxy laminate.

It should be mentioned that built into the constitutive model is the ability to define damage and modulus reduction laws that are more complex (involving fibre and matrix damage initiation and saturation values for instance) than the linear relationships assumed in this study. The reader is referred to Williams et al. [31] for complete details. However, in this body of work it was our intention to simplify the model without compromising its physical basis. To this end, the initial modulus, peak stress and fracture energy were identified as the primary model parameters.

\subsubsection{Scaling for Numerical Objectivity}

Finite element simulations using strain-softening material models are inherently mesh dependent due to localization ([8], [32] and [33]). Localization is the condition where damage becomes concentrated in a single element, or row of elements. The energy absorbed through failure of each element is dictated by the defined elemental stress-strain behaviour and the dimensions of the element. The results therefore are dependent on the size of the elements, and unlike typical finite element analyses, predictions do not improve (converge) with mesh refinement.

To address this mesh dependency, a scaling law has been incorporated into CODAM that modifies the elemental stress-strain response in order to maintain consistency of the characteristic fracture energy $\left(G_{f}\right)$, which is considered a material constant. The approach that follows the crack band concept developed by Bazant et al.[33] is based on the notion that the fracture energy (on a per unit area basis) associated with failure of any finite element should be equivalent to the corresponding fracture energy associated with failure of the characteristic RVE element. In other words, the following energy equivalence is enforced

$$
G_{f}=\gamma_{f}^{e} h_{\theta}
$$


where $G_{f}$ is the fracture energy per unit area, is the specific fracture energy of the element (per unit $\gamma_{f}^{e}$

volume) and is equal to the post-peak stress area under the stress-strain curve, and $h_{e}$ is the element size. In general, the process involves scaling the post-peak elemental stress-strain curve in such a way as to maintain the fracture energy constant (or satisfy Eq. (1)).

\subsubsection{Simplified Tensile Response}

As mentioned previously, it was our intention to simplify the constitutive response. The response is therefore assumed to remain linear until the peak stress, as shown in Fig. 2 (i.e. at the peak stress the damage parameter $\omega=0$ ). The post-peak response is non-linear due to the assumptions of linear damage growth (i.e. damage increasing linearly with strain) and a linear modulus reduction law (i.e. modulus decreasing linearly with damage), which when combined lead to a parabolic stress-strain curve. The initial modulus, peak stress and energy absorption characteristics are thus the only parameters required to define the constitutive relationship.

To maintain the physical basis of the model, these parameters should be based on measurements from suitable characterization tests. The modulus and peak stress values are typically measured from un-notched coupon specimens, although attention has to be given to the specimen width and edge effects when determining the peak stress values of braided materials or other composites with coarse architecture. The fracture energy $G_{f}$ is measured from tests such as Over-height Compact Tension (OCT) [34] or Compact Compression (CC) [35] that promote stable damage growth. Knowing the fracture energy and peak stress, allows one to calculate the specific fracture energy per unit volume from Eq. (1), which dictates the $\gamma_{f}^{e}$

strain-to-failure value that corresponds to the fully saturated (developed) damage state (i.e. the strain at failure is adjusted to represent the fracture energy per unit volume). 


\subsubsection{Simplified Compressive Response}

The underlying mechanisms that contribute to damage development in compression are different than those in tension. In tension, damage is introduced via matrix micro-cracks that coalesce into larger cracks and delaminations that eventually lead to fibre failure and complete loss of load carrying capacity of the laminate. In compression, matrix failure leads to the formation of micro buckling zones in fibres, kink band ([36]-[38]), as demonstrated in Fig. 3 for a simple cross-ply laminate. The kink band is characterized by the cooperative rotation of fibres into a band that develops under compressive load. Within this kink band, the fibres rotate and damage is introduced to the surrounding matrix via shearing and delamination.

Another distinguishing feature of compressive damage is that the damage height does not remain constant, as assumed in tension. Rather, the damage height increases as loading continues through a process known as band broadening. Band broadening is feasible in compression because loads can be transferred across damaged areas in compression due to direct bearing of the surfaces (i.e. load can be transferred across the kink band). Usually, upon reaching a critical stress value to form the initial kink band, the compressive failure zone broadens into the adjacent virgin material under a constant, reduced stress level (or plateau stress). As shown in other studies [35], the broadening continues to form macro-level failure mechanisms such as slip surfaces where all the fibres fracture across the width of the specimen and the laminate fails completely.

To characterize such behaviour and measure the damage parameters such as the plateau stress and fracture energy in order to establish a strain softening response under compression, tests such as Compact Compression (CC) [35] must be conducted to promote stable damage growth. Usually in such tests, the surface strains are measured using digital image correlation technique (DIC) in order to extract the parameters of the strain softening response (see [35] for more details). However, given the poor quality of the braided material and presence of many defects such as voids, dry spots and volume fraction variation through-thickness, full characterization of damage parameters proved to be difficult [39]. One main challenge in conducting compressive tests on samples with inhomogeneous fibre volume fractions (that leads to stiffness/strength variation) through the thickness is preventing bending / buckling which results in premature failure of the samples and large variability in the experimental results. To address this issue, for material characterization of current braided materials, along with uniaxial tests, 4-point bending tests and 
eccentric compression tests were also conducted [39]. Since full characterization under compression through compact compression tests were not carried out, a simplified compressive constitutive response was considered in this study. To represent the broadening of the damage zone in the braided material, the stress-strain behaviour was assumed to have the general characteristics shown in Fig. 4. As in tension, the material is assumed to behave linearly elastic up to the peak stress (A-B). It is also assumed that the propagation stress (plateau stress) is equal to the damage initiation stress (B-C). Generally speaking, the stress required to initiate the kink band is larger than the plateau stress to broaden the kink band. The simplified assumption was made in lieu of more complex strain softening curves (e.g. [35]) to mitigate the challenges of compressive characterization of the poor quality braided laminate used in this study. This response in fact represents an average smeared response for the kink band zone which includes both damage initiation and damage band broadening.

\section{Material Characterization and Calibration of the Damage Model}

To align with our attempt to simplify the finite element model, it was decided to take advantage of elastic assumptions where possible. With this in mind, the material response in transverse compression (compression in the hoop direction) and longitudinal tension (axial tension) were not characterized and instead assumed to remain in the elastic regime. This was based on the negligible amount of damage observed in these modes in the series of experimental tube crushing tests [41]. On the other hand, it was of primary importance to capture the transverse tensile and longitudinal (or axial) compressive damage properties in the model as a significant amount of energy is absorbed by damage growth in these directions (see Fig. 1). Effort was also placed on representing delamination accurately. It is worth noting that the predominant nature of the crushing process in these tubes was observed to be a stable crush progression, with damage initiating at the bottom (impact surface) and propagating up the length of the tube in a splaying type failure mode [41]. The splaying mode is characterized by formation of continuous fronds that bend outward (with plug initiator) or both outward and inward (without plug initiator) with little or no fracturing of the fibre bundles. This section presents the methodology used to characterize the relevant material properties and summarizes the final model parameters that were used in the axial crush simulations of the tubes [1]. 
In characterizing the braided material using standard mechanical coupon tests, attention must be paid to the coarse architecture of the material and the large influence that edge effects can play. Zhang et al. [21] studied the effect of free-edge on the stiffness properties of triaxially-braided composites and through their numerical and experimental investigations determined that the modulus obtained from tensile tests conducted on straight-sided coupons is size-dependent. The treatment of the edges of specimens can also be influential. For example, Pickett and Fouinneteau [30] noted up to a $28 \%$ reduction in the failure stress and a $39 \%$ reduction in the failure strain of braided coupon specimens when tested with cut edges versus uncut edges (continuous tows achieved by reversing their direction at the edge). Aggarwal et al. [26] noted even more significant differences (up to $60 \%$ reductions) in carbon fibre/epoxy braided specimens. Given that in most applications (e.g. braided composite tubes) the braid is continuous, basing material model parameters on tests conducted on coupons cut from a larger panel can lead to large model errors. For these reasons, it was decided to determine the model parameters using tests that are as insensitive to edge effects as possible.

\subsection{Transverse (Hoop) Tensile Response Characterization}

Although the failure strength and strain values were extremely sensitive to edge effects, both Aggarwal [29] and Pickett and Fouinneteau [30] noted that there was little influence of the edge treatment on the initial modulus values. However, to address the concerns regarding edge effects, elastic and damage properties obtained by standard tests were further verified using tests conducted on notched samples, as discussed in the next section. While other studies (e.g. [26]-[28]) have also recommended using notched samples to minimize the edge effects when characterizing braided materials, the notched sample geometry used in this study is such that it promotes a self-similar damage growth to enable fracture characterization. In the current study, the initial modulus was assumed to be equal to $12.5 \mathrm{GPa}$, based on coupon tests carried out by Huang and Waas on the braided material [39]. The validity of this modulus was then verified by conducting numerical simulations of notched tests (see Section 4.1.2 below). The other parameters needed for characterization of the material in this direction are the fracture energy, $G_{f}$, and the peak strength, $\sigma_{p}$. Quantification of these two parameters, using a combined numerical and experimental approach, is outlined in the following sections. 


\subsubsection{Fracture Energy Characterization}

To obtain fracture energy, tensile fracture tests were conducted on the 2-ply and 4-ply braids using the Over-height Compact Tension (OCT) specimen geometry (Fig. 5(a)) established by Kongshavn and Poursartip [34]. Specimens were loaded in tension through pins located above and below the notch to promote stable progressive crack growth. The load and pin opening displacement were recorded throughout the test and deformation and strain development on the surface of the specimens was monitored using the DIC technique. Fig. 6 shows a force vs. pin opening displacement (POD) profile representative of the 4-ply braided material, along with the crack length $(\Delta a)$ at four different locations as determined from the strain contours. An average value of $G_{f}$ is calculated as the total work done by the forces applied at the pins divided by the area of crack length as:

$$
G_{f}=\frac{W_{\text {total }}}{t(\Delta a)}
$$

where $W_{\text {total }}$ is the total work done, $t$ is the thickness of the specimen, and $\Delta a$ is the crack length. The total work done at a given value of POD was calculated as the area under the load-POD curve assuming unloading along a linear path to zero load and zero POD (i.e. permanent deformation was not considered). Using this approach, the characteristic fracture energies were determined to be 47 and $55 \mathrm{~kJ} / \mathrm{m}^{2}$ for the 2ply and 4-ply braided material, respectively.

\subsubsection{Tensile Peak Strength}

As explained earlier, due to the poor quality of the material and variation of stiffness through the thickness, bending of the samples during uniaxial tests was unavoidable. This resulted in premature failure of the specimens. While Huang and Waas [39] report an average peak strength value of $47 \mathrm{MPa}$ based on standard coupon testing (about 0.4\% strain-to-failure), other studies such as Aggarwal [29] and Pickett and Fouinneteau [30], report a higher range of 67 to $120 \mathrm{MPa}$ (about $0.6 \%$ to $1 \%$ strain-to-failure). Huang and Waas [39] reported a large difference between the strains measured from both surfaces of each specimen 
during each test (up to $0.3 \%$ in some cases) which underscores the issue with the bending of the samples and premature failure. Based on these experimental results, an initial wide range of 47 to $130 \mathrm{MPa}$ (corresponding to strain-to-failure values ranging from $0.4 \%$ to $1 \%$ ) was considered for tensile strength. To further improve the estimation of the peak strength and narrow down the wide range of experimental values, a series of finite element simulations were conducted using the OCT geometry. Because damage localizes into a single row of elements in simulations using strain softening approaches, in the OCT simulations, a structured mesh with uniform element size of $2 \mathrm{~mm}$ was placed in front of the notch and assigned a damage model (CODAM) while outside this zone the material was considered to be linear elastic (see Fig. 7). The obtained fracture energy from the previous section along with the wide range of experimental peak stresses were used as CODAM input parameters for these simulations. By correlating the experimental results with numerical load-displacement curves, the estimated value for the peak strength was further refined. For each simulation, the peak strength was varied while keeping the initial elastic modulus and fracture energy constant. In order to maintain the objectivity of the numerical simulations, the Bazant's crack band scaling [33], as described in the previous sections, was used to determine the fracture energy density, and consequently the saturation strain, in the linear strain-softening curve. As an illustrative example, the input curves for the two peak stress values of $47 \mathrm{MPa}$ and $118 \mathrm{MPa}$ that represent the same fracture energy values (for a $2 \mathrm{~mm}$ mesh size) are shown in Fig. 8.

Both 2-ply and 4-ply OCT specimens were simulated using LS-DYNA and the implemented CODAM damage model. For the 4-ply simulations the initial modulus and lower bound peak strength were increased by $10 \%$ to represent the fact that the 4-ply material was of better quality (also likely the main contributing factor to the higher characteristic fracture energy, which was $17 \%$ higher in the thicker material). The final input material parameters for the two simulations that produced the most reasonable predictions are summarized in Table 2. Fig. 9 shows the response predicted using these material parameters as well as the predicted response assuming the peak strength values of $47 \mathrm{MPa}$ and $52 \mathrm{MPa}$ (lower bound experimental results). Using this numerical approach, the peak strength values for these braided materials are estimated through a trial-and-error scheme to be $118 \mathrm{MPa}$ and $130 \mathrm{MPa}$ for the 2-ply and 4-ply systems, respectively. It can be observed that for the 4-ply system (Fig. 9b) the initial elastic part of the simulated curve as well as the response near the peak loads agrees well with the experimental data. This agreement is 
carried over into the post-peak (softening) portion of the curve where the predicted softening response falls within the scatter band of the experimental results; thus indicative of a smooth progressive growth of damage. In contrast, the sudden drops in load observed experimentally for the 2-ply specimens that are not captured in the simulation results, are caused by the sudden formation of cracks likely due to the inferior quality of the thinner specimens. The smeared crack approach adopted in the current numerical model is more suitable for predicting stable and progressive crack growth as opposed to abrupt load drops that are driven by local material instabilities. Therefore, the predicted post-peak softening behaviour tends to be smooth, characterized by a shallow descending slope as shown in Fig. 9.

\subsection{Axial (Longitudinal) Compressive Response Characterization}

The initial modulus in the longitudinal direction (parallel to the axial tows) was assumed to be equal to 60 GPa based on coupon tests carried out by Huang and Waas [39]. For the assumed simplified stress-strain curve (as shown in Fig. 4), only the initial modulus and compressive strength have to be defined. The axial compressive strains induced in the splaying fronds of the tubes during crushing were not large enough to cause fully saturated $(100 \%)$ damage. As a result failure strain does not need to be defined in order to accurately capture this particular crushing event. As mentioned earlier, due to the difficulties associated with conducting axial compressive tests on the poor quality braided materials considered in this study, the compressive strength of the material was estimated from 4-point bend tests carried out by Huang and Waas [39]. Given that composites, and especially braided or woven composites, are weaker in compression than in tension, the onset of damage and thus deviation from linearity is associated with compressive damage initiation in these tests.

Ten four-point bend specimens (Fig. 10), having a length, $L$, of either $17.78 \mathrm{~cm}$ (7 in) or $22.86 \mathrm{~cm}$ (9 in) and other dimensions as summarized in Table 1, were tested with the axial tows aligned with the length of the specimen. The experimental load versus load cell displacement profiles were compared to elastic solutions (see Fig. 11) to identify the location where the experimental curves become non-linear (an indication of damage initiation). The compressive stress in the outer fibre corresponding to these locations is calculated as

$$
\sigma_{c r i t}=\frac{3 P d}{w t^{2}}
$$


where $P$ is the load, $d$ is the distance between the point of load application and support (as shown in Fig. 10), and $w$ is the specimen width. This provides an estimate for the compressive strength ranging from 210 to $280 \mathrm{MPa}$. An average value of $250 \mathrm{MPa}$ is assumed in this study.

\subsubsection{Validation using Eccentric Compression Simulations}

To validate the simplified compression model with compressive properties obtained above, eccentric compression tests conducted by Huang and Waas [39] on the same braided material were simulated in LSDYNA. The eccentric compression test configuration induces large rotations during bending of the specimen leading to possible hinge formation at the centre of the beam which mimics the type of deformation mechanisms that the fronds of the tube undergo as they bend around the plug initiator (in the case of tube crush with plug initiator) or around the debris wedge (in the case of tube crush without plug initiator). Details of the eccentric compression tests have been described in [42]. Huang and Waas [39] tested sixty combined compression-bending (eccentric compression) specimens having lengths of 15.24, $17.78,20.32$ and $22.86 \mathrm{~cm}(6,7,8$ and $9 \mathrm{in})$ and eccentricities of 2,7 and $14 \mathrm{~mm}$. The specimens were nominally $50 \mathrm{~mm}$ wide and $2.2 \mathrm{~mm}$ thick. In the experiments, the load was applied and monitored through special eccentric grips and a RVDT was attached to the bottom of the jig to record the end rotation. Specimens failed catastrophically via cracking and hinge formation at the middle of the specimen.

The numerical eccentric compression model consisted of one layer of shell elements, discretized in-plane with $4 \times 4$ mesh of elements with thickness of $2.2 \mathrm{~mm}$. The ends of the specimen were rigidly attached to two rigid plates at the top and the bottom with a width of 2,7 or $14 \mathrm{~mm}$. Displacements were applied to the edges of the rigid plates to represent the eccentricity of the applied loads (Fig. 12b). The material was assumed to have a modulus of $60 \mathrm{GPa}$ and a compressive strength of $250 \mathrm{MPa}$. The material was also assumed to remain elastic and undamaged in tension.

Fig. 12(a) compares the LS-DYNA predictions to the experimental load versus end rotation response for the 7in length with an eccentricity of $e=7 \mathrm{~mm}$. The specimen bends under the eccentric compressive loads and reaches a peak load after an end rotation of approximately $25^{\circ}$ (or an applied displacement of $12 \mathrm{~mm}$ ). The load then drops off continuously until the end of the simulation. Note that because the tensile response is elastic, the simulation does not predict failure (or hinge formation) as was observed experimentally. Aside from one experimental outlier, the predictions agree well with the experiments. Also shown on the 
same figure are two more curves predicted by LS-DYNA. The first corresponds to the predicted response if the material is assumed to behave elastically (i.e. no damage) in both tension and compression. The prediction representing damage growth diverges from this elastic solution at a load of approximately $580 \mathrm{~N}$ (or at the instant when the maximum outer fibre compressive stress reaches -250 MPa). The second curve corresponds to the response if the material strength values are based on results from coupon testing (in this case equal to $170 \mathrm{MPa}$ and $109 \mathrm{MPa}$ in tension and compression, respectively). This results in very poor predictions, supporting the claim that edge effects play a significant role in coupon testing of this braided material.

The numerically obtained peak loads and average of the experimentally measured peak loads are compared for the twelve variations of the tests in Fig. 13. The peak loads were slightly over-predicted in the shorter 6in specimens and under-predicted for the other three lengths. However, most simulation results fell within the bounds of the experiments.

\subsection{Interfacial Delamination Properties}

Delamination is also an important mode of failure that needs to be represented in the model to properly capture the behaviour of multi-ply braided composite tubes under axial load. Fracture energy required to simulate delamination was determined from DCB tests conducted by Keller et al. [43] on 4-ply [0/土45] braided materials. From these tests, an average fracture energy value, $G_{I c}$, of about $1.7 \mathrm{~kJ} / \mathrm{m}^{2}$ was measured. Similar values for delamination fracture energy were also reported in a study by Mouritz et al. [44] based on DCB tests on braided $[0 / \pm 45]_{6}$ laminates. They attributed this rather high value to extensive branching of the crack around the braided fibre bundles, as noted in SEM micrographs of cross-sections taken from the DCB specimen after testing.

\section{Tube Crushing Simulation}

Table 2 provides a summary of the input parameters for crush simulations of braided tubes. This table also presents the summary of the experimental and numerical methods used to obtain these parameters. For tube crush simulations, the strain-softening constitutive responses in tension and compression along the transverse (hoop) and axial directions, respectively, are constructed using these parameters. For current simulations, rate dependency of the material was neglected. This decision was supported by experimental results conducted at intermediate strain rates of $1 / \mathrm{s}$ [45]. The experiments showed negligible enhancement 
of material properties (increases in strength and stiffness) at these rates. In other studies, it has been shown that there is a perceptible change in mechanical properties at very high strain rates (exceeding $5001 / \mathrm{s}$ ). However, at the global rates of loading relevant to the tube crushing events considered in this study $(<100$ 1/s) an insignificant change in properties has been reported. When testing braided composites, Sun and coworkers [46] observed negligible change in tensile stiffness for strain rates less than $2501 / \mathrm{s}$. In a separate study [47], while the compressive response was found to be highly influenced at elevated rates above 1600 $1 / \mathrm{s}$, very little effect on mechanical properties was observed at strain rates below $4001 / \mathrm{s}$.

The material behaviour under axial tension and transverse compression are assumed to be linear elastic (without damage) given that in the tube crush event these are not the operative modes of loading. For both 2-ply and 4-ply tubes, intra-laminar damage response of individual plies were simulated using material model CODAM implemented in LS-DYNA as a user material model. A mesh size of $2 \mathrm{~mm}$ was used in these simulations (for more details refer to [1]). The built-in "tie-break" interface option (*CONTACT AUTOMATIC ONE WAY SURFACE TO SURFACE TIEBREAK) was used to simulate delamination. It has been shown that the fracture energy of the tie-break model is the primary parameter that drives the response and other numerical parameters such as the combination of failure stress and PARAM values are of secondary importance ([48]-[50]).

Contact between the tube and the plug initiator, debris wedge and rigid wall were modeled using *CONTACT_AUTOMATIC_SURFACE_TO_SURFACE. Based on measurements made by DeTeresa et al. [45] on a similar braided material, a coefficient of friction of 0.22 was used between the tube and the plug. A higher value of 0.35 was used between the tube and the rigid wall to account for the fact that the surfaces of the plies were rougher in tubes crushed without the plug initiator. DeTeresa et al. measured an average value of 0.35 in their friction tests when the surface of the braid was roughened. Owing to the highly abrasive nature of the debris wedge, an even higher value of 0.40 was assumed for contact between the tube and the debris wedge.

In the drop weight simulations only a quarter of the tube was modeled due to symmetry. The drop weight was simulated as a rigid body with a quarter of the total mass of $535 \mathrm{~kg}$. An initial velocity of 2.6 to $4.9 \mathrm{~m} / \mathrm{s}$ was applied to the drop weight. Similar to experiments, all the simulations were conducted with and without an external plug initiator. Fig. 14 shows a comparison of the experimental and numerical failure 
morphology for 2-ply and 4-ply tube crushing simulations without a plug. Experimental and numerical force-displacement curves are also compared in Fig. 15.

To gauge the crashworthiness of the tubes, two main parameters that are usually considered are the specific energy absorption (SEA) and load ratio, defined as the ratio of peak load to the average load. Comparison of these values obtained from experiments and simulations are shown in Fig. 16.

SEA values show an acceptable agreement with only $4 \%$ difference between experimentally measured and predicted values. The predicted load ratios, however, do not match as closely as the SEA and show a maximum of $40 \%$ difference for simulations with plug and $8 \%$ for simulations without plug. As reported in other studies [1], the difference observed in simulations with a plug can be attributed to the difficulties associated with accurately capturing the chamfer at the leading edge of the tube as well as development of the debris wedge in the numerical model. Fig. 16 also shows the predicted breakdown of energy absorption between the three energy absorbing mechanisms, namely, delamination, friction, and material damage. The numerical results suggest that the majority of the energy is absorbed through material damage, followed by friction, and finally by energy absorbed through delamination, which is relatively insignificant at only $1-3 \%$. However, representing delamination in the model is crucial in capturing the correct load path and failure morphology (i.e. splaying).

\section{Conclusions}

During axial crushing of braided composite tubes, the energy absorbed by the material is primarily a result of progression of compressive damage in the longitudinal (or axial) direction, tensile damage in the hoop (or transverse) direction, and delamination.

In this paper, a previously developed continuum damage mechanics based model, CODAM, was used to represent the consequence of damage propagation in a carbon fibre/epoxy $[0 / \pm 45]$ braided composite. The inputs to the model are initial elastic moduli, peak stress values and fracture energy. In compression, band broadening or propagation of the initial damage unit into the interior undamaged material, is represented by a plateau stress. The input parameters were determined from a series of specialized tensile fracture experiments conducted in-house, combined with standard coupon and 4-point bend test results reported previously [39]. Very good agreement between the simulations and the experiments was observed, 
indicating that despite some simplifying assumptions that were made, the pertinent details of the material behaviour were captured.

The input material stress-strain (strain-softening) curves determined from this study have been used successfully to simulate the damage propagation and energy absorption in the axial crushing of braided composite tubes.

\section{Acknowledgements}

The authors gratefully acknowledge the interaction with General Motors Corporation. This project was supported by General Motors of Canada Ltd. and the Natural Sciences and Engineering Research Council of Canada (NSERC) under a collaborative research and development grant. The authors would like to thank Roger Bennett and Julien Michelet for their help with the experiments. This paper used experimental data from references [39] and [43], which were generated in research projects supported by Department of Energy cooperative agreement no. DE-FC05-95OR22363. Such support does not constitute an endorsement by the Department of Energy of the views expressed herein.

\section{References}

1. McGregor, C., Vaziri, R. and Xiao, X., "Finite Element Modelling of the Progressive Crushing of Braided Composite Tubes under Axial Impact", Int. J. Impact Engineering, Vol. 37(6), pp. 662-672, 2010 .

2. Li X, Hallett SR, Wisnom MR, Zobeiry N, Vaziri R, Poursartip A. Experimental study of damage propagation in over-height compact tension tests, Composites Part A: Applied Science and Manufacturing, 2009; 40(12): 1891-1899.

3. Xu X, Wisnom MR, Mahadik Y, Hallett SR. Scaling of fracture response in Over-height Compact Tension tests, Composites Part A: Applied Science and Manufacturing, 2015;69:40-48.

4. Kaddour AS, Hinton MJ, Smith PA, Li S. Special Issue: Benchmarking of matrix cracking, damage and failure models for composites: Comparison between theories: Part A of The Third World-Wide Failure Exercise (WWFE-III), Journal of Composite Materials, 2013; 47(20-21).

5. Camanho, PP, Davila, CG, de Moura, MF. Numerical simulation of mixed-mode progressive delamination in composite materials. J Compos Mater, 2003; 37(16):1415-1438.

6. Maimi, P. Camanho, PP, Mayugo, JA, Davila, CG. A continuum damage model for composite laminates: Part I - constitutive model. Mech. Mater., 2007; 39(10):897-908.

7. Talreja, R. Continuum mechanics characterization of damage in composite materials. Proc. R. Soc. Lond. , Ser. A: Math. Phys. Sci., 1985; 399(1817):195-216.

8. Ladeveze, P, Allix, O, Deu, J, Leveque, D. Mesomodel for localisation and damage computation in laminates. Comput. Methods Appl. Mech. Eng., 2000; 183(1):105-122. 
9. Zobeiry, N, Forghani, A, McGregor, C, Vaziri R, Poursartip, A. Progressive damage modeling of composite materials under both tensile and compressive loading regimes. Mechanical Response of Composites', Series: Computational Methods in Applied Sciences, Springer, 2008; 10:179-195.

10. Zobeiry, N, Forghani, A, McGregor, C, McClennan S, Vaziri R, Poursartip, A. Effective calibration and validation of a nonlocal continuum damage model for laminated composites. Submitted to: Composite Structures, 2016.

11. Song, S, Waas, AM, Shahwan, KW, Xiao, X, Faruque, O. Braided textile composites under compressive loads: modeling the response, strength and degradation. Composites Science and Technology, 2007; 67(15), 3059-3070.

12. Song, S, Waas, AM, Shahwan, KW, Faruque, O, Xiao, X, Compression response of 2D braided textile composites: single cell and multiple cell micromechanics based strength predictions. Journal of composite materials, 2008; 42(23);2461-2482.

13. Kueh, AB, Size-influenced mechanical isotropy of singly-plied triaxially woven fabric composites. Composites Part A: Applied Science and Manufacturing, 2014; 57:76-87.

14. $\mathrm{Xu}, \mathrm{L}, \mathrm{Jin}, \mathrm{CZ}, \mathrm{Ha}, \mathrm{SK}$, Ultimate strength prediction of braided textile composites using a multiscale approach. Journal of Composite Materials, 2015; 49(4):477-494.

15. Li, X, Binienda, WK, \& Littell, JD, Methodology for impact modeling of triaxial braided composites using shell elements. Journal of Aerospace Engineering, 2009; 22(3):310-317.

16. Cheng, J, Binienda, WK, Simplified braiding through integration points model for triaxially braided composites. Journal of Aerospace Engineering, 2008; 21(3):152-161.

17. Xiao, X, Kia, HG, Gong, XJ, Strength prediction of a triaxially braided composite. Composites Part A: Applied Science and Manufacturing, 2011; 42(8):1000-1006.

18. Zhang, C, Binienda, WK, Kohlman, LW, Analytical model and numerical analysis of the elastic behavior of triaxial braided composites. Journal of Aerospace Engineering, 2013; 27(3):473-483.

19. Cater, C, Xiao, X, Goldberg, RK, Kohlman, LW, Experimental and Numerical Analysis of Triaxially Braided Composites Utilizing a Modified Subcell Modeling Approach, NASA document\# 20160001347, 2015.

20. Zhang, C, Binienda, WK, Goldberg, RK, \& Kohlman, LW, Meso-scale failure modeling of single layer triaxial braided composite using finite element method. Composites Part A: Applied Science and Manufacturing, 2014; 58:36-46.

21. Zhang, C, Binienda, WK, \& Goldberg, RK, Free-edge effect on the effective stiffness of singlelayer triaxially braided composite. Composites Science and Technology, 2015; 107:145-153.

22. Zhang, C, Li, N, Wang, W, Binienda, WK, Fang, H, Progressive damage simulation of triaxially braided composite using a 3D meso-scale finite element model. Composite Structures, 2015; 125:104-116.

23. Zobeiry, N, Forghani, A, Li, C, Thorpe, R, Gordnian, K, Vaziri, R., Fernlund, G, Poursartip, A, Multi-scale characterization and representation of composite materials during processing, Philosophical Transactions of the Royal Society of London A: Mathematical, Physical and Engineering Sciences, A 374, no. 2071 (2016): 20150278. 
24. Borkowski, L, Chattopadhyay, A, Multiscale model of woven ceramic matrix composites considering manufacturing induced damage. Composite Structures, 2015; 126:62-71.

25. Brimhall, T.J. "Friction Energy Absorption in Fibre Reinforced Composites," Ph. D Thesis, Department of Mechanical Engineering, Michigan State University, Michigan, USA, 2005.

26. Kohlman, LW, Bail, JL, Roberts, GD, Salem, JA, Martin, RE, Binienda, WK, A notched coupon approach for tensile testing of braided composites. Composites Part A: Applied Science and Manufacturing, 2012; 43(10), 1680-1688.

27. Kohlman, LW, Evaluation of test methods for triaxial braid composites and the development of a large multiaxial test frame for validation using braided tube specimens (Doctoral dissertation, The University of Akron), 2012.

28. Littell, J, The experimental and analytical characterization of the macromechanical response for triaxial braided composite materials (Doctoral dissertation, University of Akron), 2008.

29. Aggarwal, A., Ramakrishna, S. and Ganesh, V.K., "Predicting the Strength of Diamond Braided Composites," Journal of Composite Materials, vol. 36, pp. 625-643, 2002.

30. Pickett, A.K. and Fouinneteau, M.R.C., "Material Characterisation and Calibration of a MesoMechanical Damage Model for Braid Reinforced Composites," Composites Part A: Applied Science and Manufacturing, vol. 37, pp. 368-377, 2006.

31. Williams, K.V., Vaziri, R. and Poursartip, A., "A Physically Based Continuum Damage Mechanics Model for Thin Laminated Composite Structures," International Journal of Solids and Structures, vol. 40, pp. 2267-2300, 2003.

32. Belytschko, T., Bazant, Z.P., Hyun, Y. and Chang, T.-., "Strain-Softening Materials and FiniteElement Solutions," Computers and Structures, vol. 23, pp. 163-180, 1986.

33. Bazant, Z. P. and Planas, J. , Fracture and Size Effect in Concrete and Other Quasibrittle Materials. CRC Press, 1998.

34. Kongshavn, I. and Poursartip, A., "Experimental Investigation of a Strain-Softening Approach to Predicting Failure in Notched Fibre-Reinforced Composite Laminates," Composites Science and Technology, vol. 59, pp. 29-40, 1999.

35. Zobeiry, N., Vaziri, R. and Poursartip, A. "Characterization of Strain-Softening Behaviour and Failure Mechanisms of Composites under Tension and Compression", Composites Part A: Applied Science and Manufacturing, Vol. 68, pp. 29-41, 2015

36. Fleck,N.A., "Compressive Failure of Fiber Composites," Advances in Applied Mechanics, vol. 33, pp. 43-113, 1997.

37. Moran, P.M. and Shih, C.F., "Kink Band Propagation and Broadening in Ductile Matrix Fiber Composites: Experiments and Analysis," International Journal of Solids and Structures, vol. 35, pp. 1709-1722, 1998.

38. Sivashanker, S., Fleck, N.A. and Sutcliffe, M.P.F., "Microbuckle Propagation in a Unidirectional Carbon Fibre-Epoxy Matrix Composite," Acta Materialia, vol. 44, pp. 2581-2590, 1996. 
39. Huang, H.J. and Waas, A.M., "Data acquisition for progressive failure in braided textile composites," Composites Structure Laboratory, University of Michigan, Ann Arbor, MI 48109-2140, 2004

40. McGregor, C., Zobeiry, N., Vaziri, R. and Poursartip, A., "A Constitutive Model for Progressive Failure of Composites," J. Composite Materials, Vol. 42(25), pp. 2687-2716, 2008.

41. McGregor, C., Vaziri, R., Poursartip, A. and Xiao,X., "Axial Crushing of Triaxially Braided Composite Tubes at Quasi-static and Dynamic Rates," Composite Structures, vol. 157, pp. 197-206, 2016.

42. Quek, S.C., Waas, A.M., Shahwan, K.W. and Agaram, V., "Failure Mechanics of Triaxially Braided Carbon Composites Under Combined bending-compression Loading," Composites Science and Technology, vol. 66, pp. 2548-2556, 11. 2006.

43. Keller, J., Kjerengtroen, L. and Cross, W., "Final report: Interfacial analysis of ACC composite samples," Report submitted to Automotive Composites Consortium (ACC), South Dakota School of Mines \& Technology, May 9, 2008.

44. Mouritz, A.P., Baini, C. and Herszberg, I., "Mode I Interlaminar Fracture Toughness Properties of Advanced Textile Fibreglass Composites," Composites - Part A: Applied Science and Manufacturing, vol. 30, pp. 859-870, 1999.

45. DeTeresa, S.J., Allison, L.M., Cunningham, B.J., Freeman, D.C., Saculla, M.D., Sanchez, R.J.,and Winchester, S.W., "Experimental results in support of simulating progressive crush in carbon-fiber textile composites", Lawrence Livermore National Laboratory, UCRL-ID-143287, March12, 2001.

46. Sun, B, Liu, F, Gu, B, Influence of the strain rate on the uniaxial tensile behavior of 4-step 3D braided composites. Composites Part A: Applied Science and Manufacturing, 2005; 36(11), 1477-1485.

47. Sun, B, Gu, B, High strain rate behavior of 4-step 3D braided composites under compressive failure. Journal of materials science, 2007; 42(7), 2463-2470.

48. Forghani, A., McGregor, C., McClennan, S., et al, Modelling of damage development in blast loaded composite panels. In: 16th International Conference on Composite Materials (ICCM-16), Kyoto, Japan, 8-13, July 2007.

49. Forghani, A. and Vaziri, R., "Computational modeling of damage development in composite laminates subjected to transverse dynamic loading, " Journal of Applied Mechanics, Transactions ASME, Special Issue on Impact Engineering, Vol. 76, pp. 051304-1 to 051304-11, 2009.

50. Alfano, G. and Crisfield, M.A., "Finite element interface models for the delamination analysis of laminated composites: Mechanical and computational issues, " International Journal for Numerical Methods in Engineering, vol. 50(7), pp.1701 - 1736, 2001. 


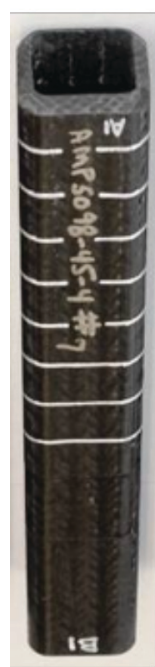

(a)

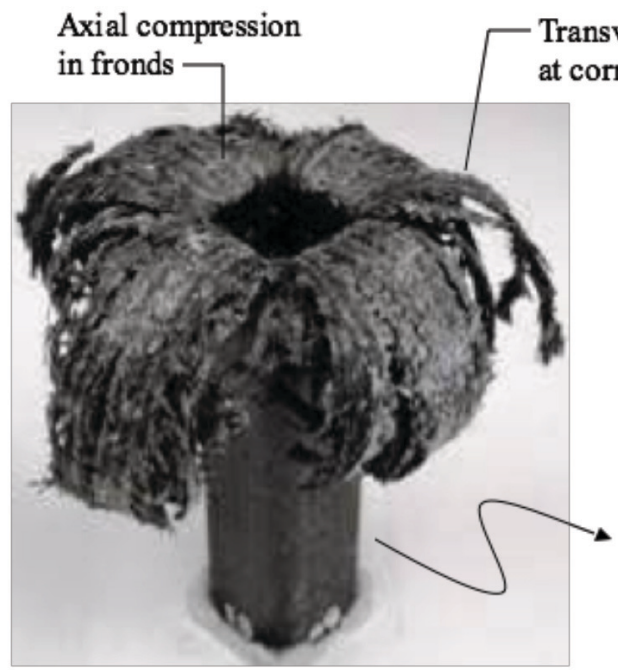

(b)

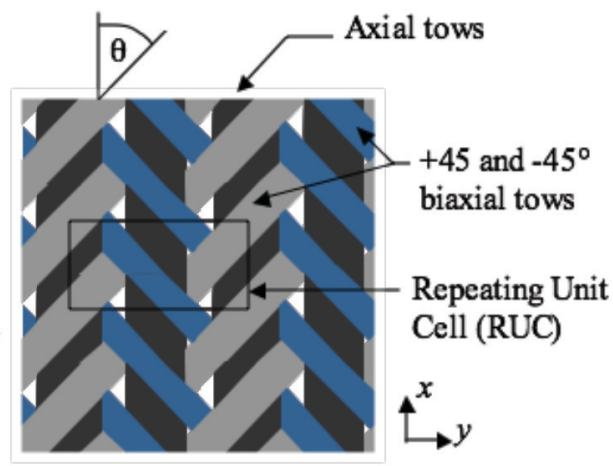

(c)

Fig. 1. Braided composite tube (a) before and (b) after dynamic axial crushing test and (c) schematic showing the corresponding architecture of the $[0 / \pm 45]$ braid.

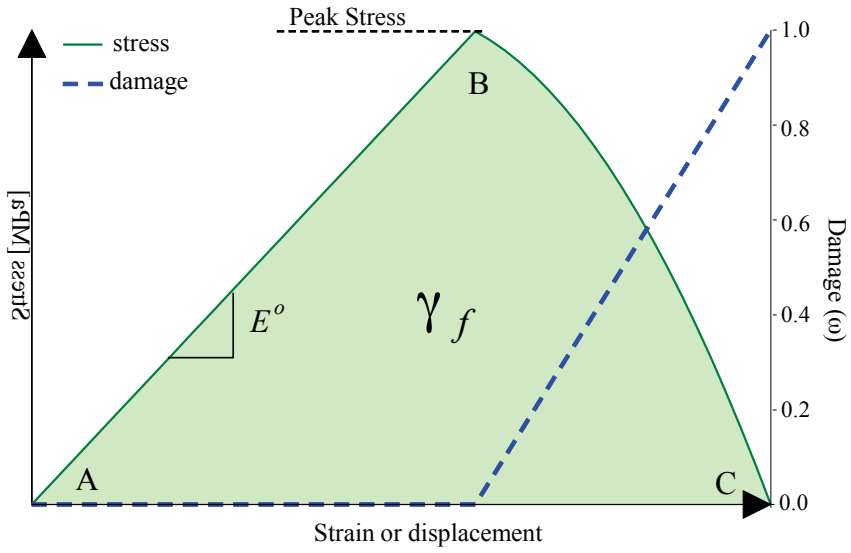

Fig. 2. General strain-softening response used to represent the behaviour and energy absorbed through tensile fracture. 


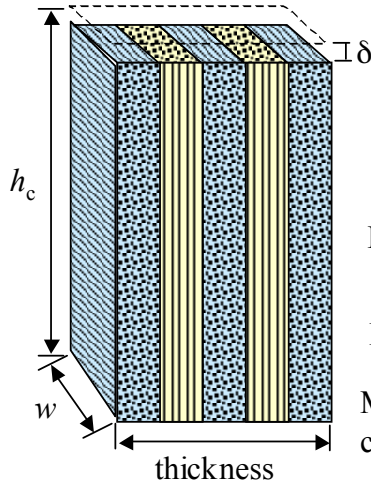

(a)

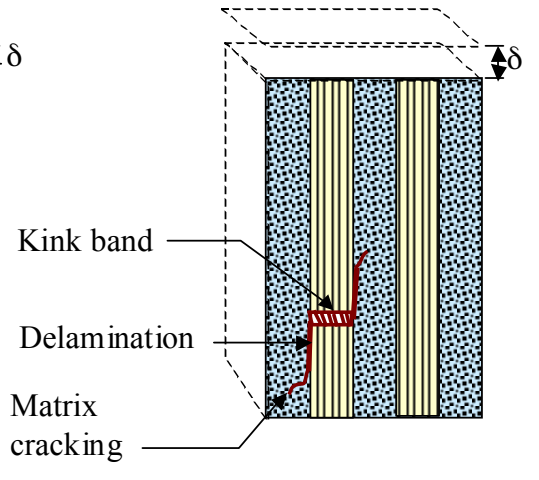

(b)

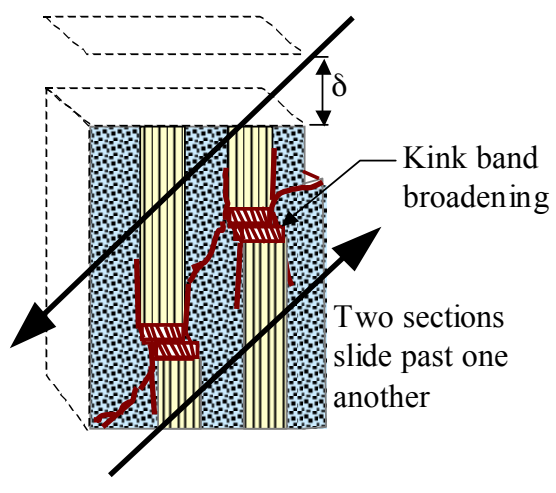

(c)

Fig. 3. Schematic showing progression of the through-thickness damage in compression from (a) undamaged to the state of (b) damage initiation via kinking and matrix damage and (c) complete failure represented by fibre fracture and matrix cracking across the specimen width.

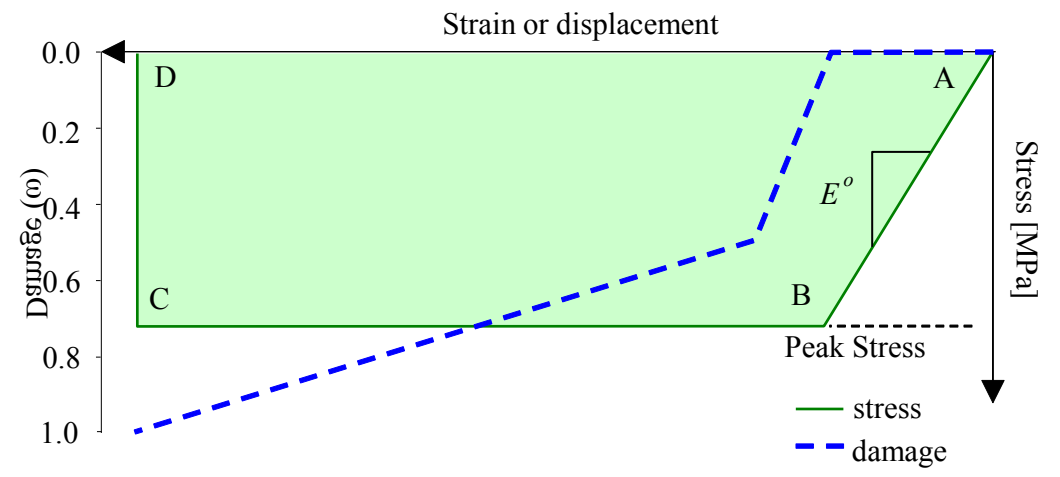

Fig. 4. Simplified stress-strain response used to represent the behaviour and energy absorbed through compressive fracture. Note that the damage law is not linear as in tension, but rather bi-linear. This is due to features of the constitutive model related to the definition of damage growth within each of the constituents (matrix and fibre) - see [40]. 


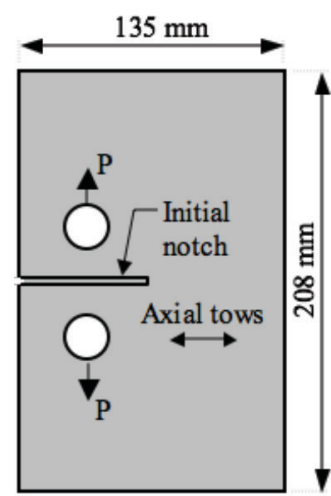

(a)

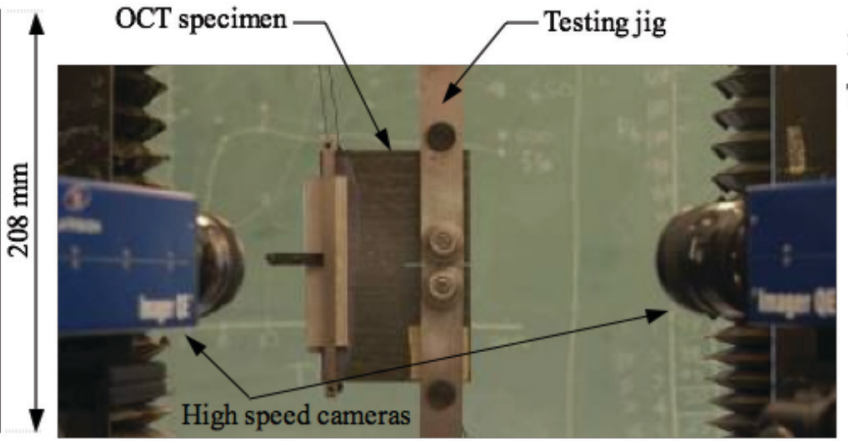

(b)

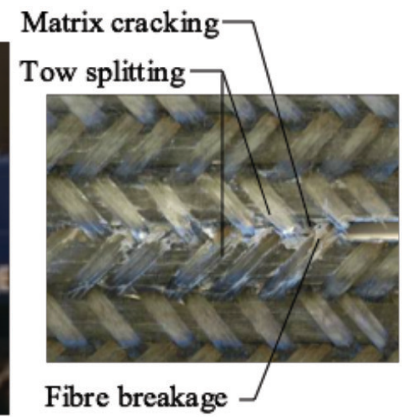

(c)

Fig. 5. (a) OCT specimen geometry, (b) experimental set-up and (c) details of the damage observed ahead of the notch.

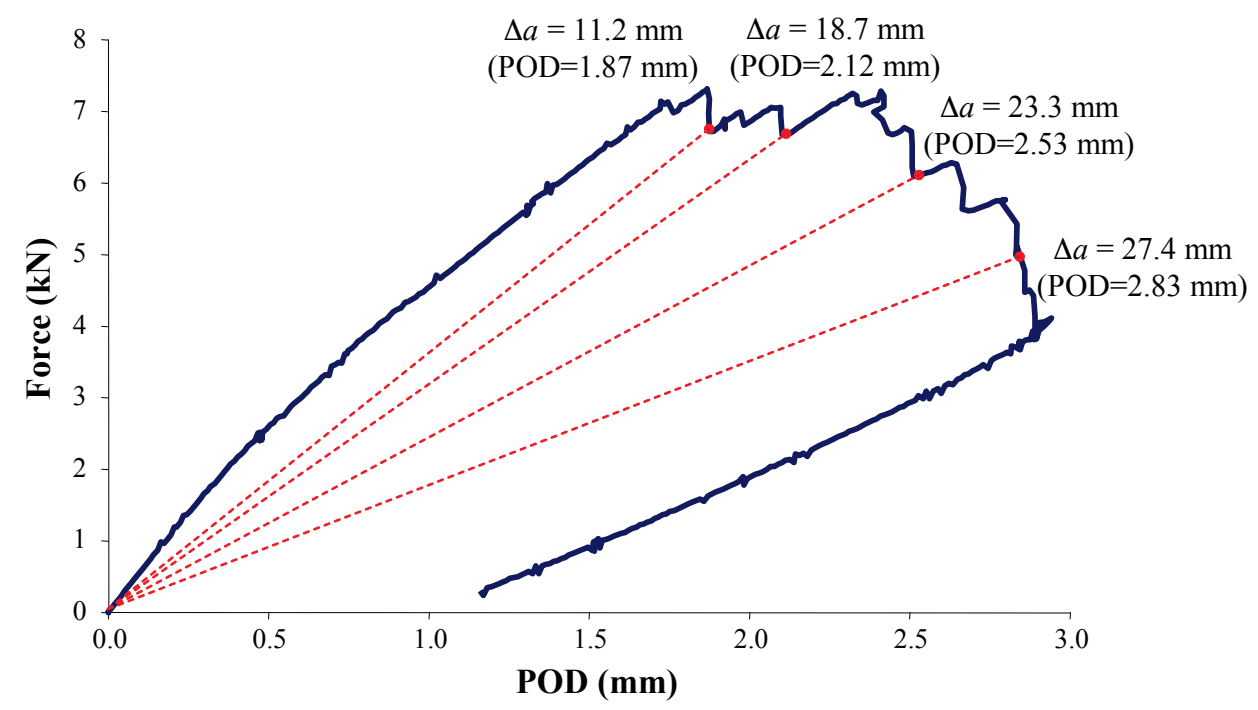

Fig. 6. Load versus POD profile for a 4-ply braided OCT test, showing the crack length associated with increasing levels of POD. 

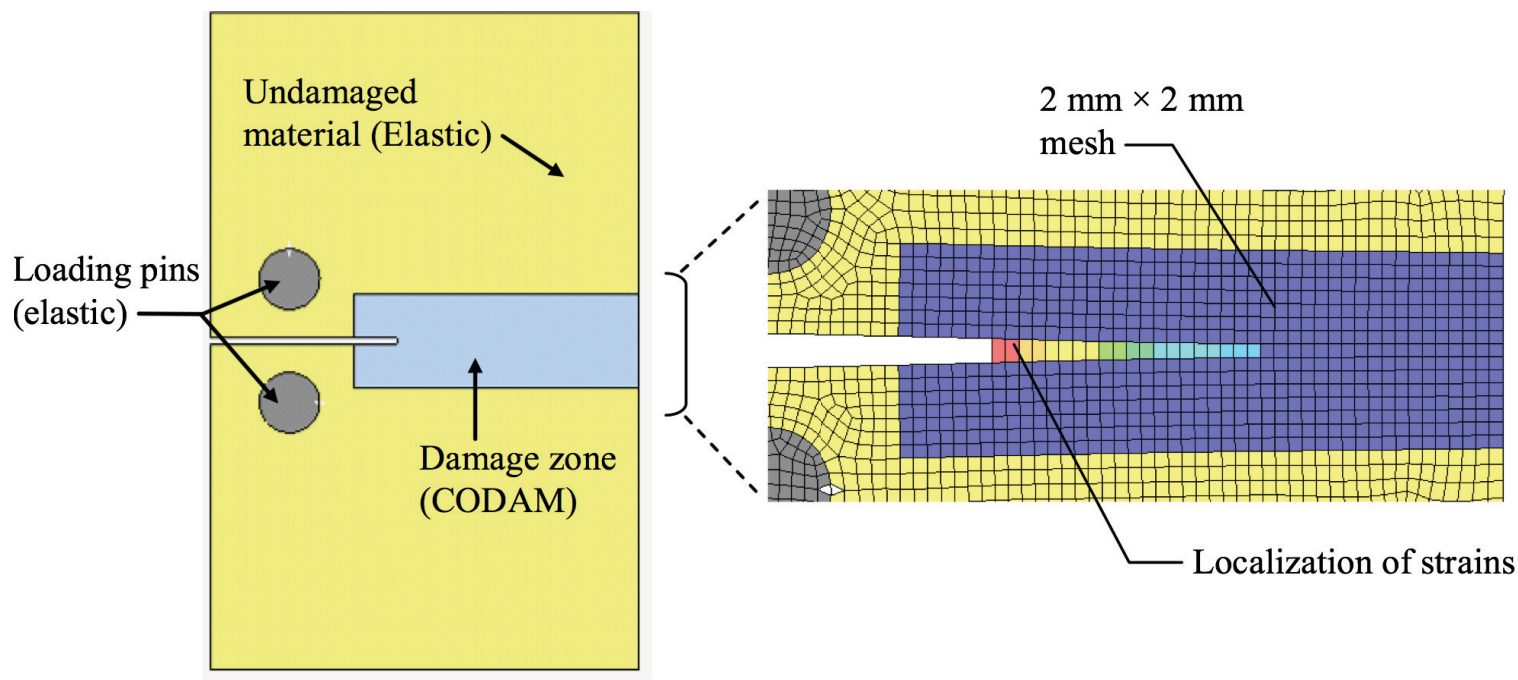

Fig. 7. Details of the OCT model in LS-DYNA showing the localization of strains into a single row of elements in front of the notch.

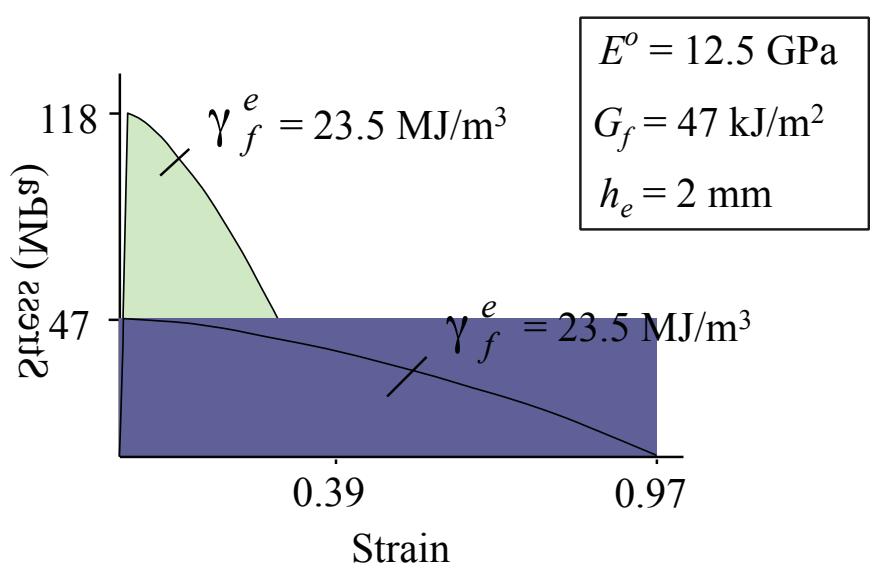

Fig. 8. Schematic showing the method used to scale the peak strength value while maintaining the other material parameters; namely, the elastic modulus and fracture energy density (or area under the stress-strain curve) for a $2 \mathrm{~mm}$ element constant. 


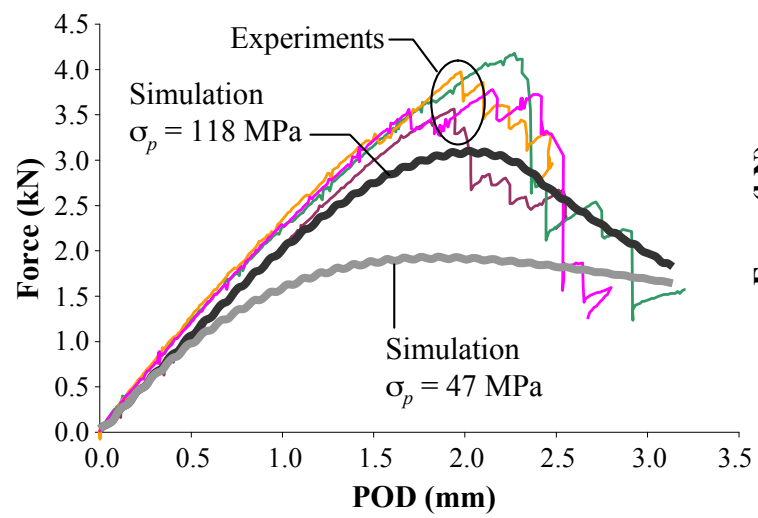

(a)

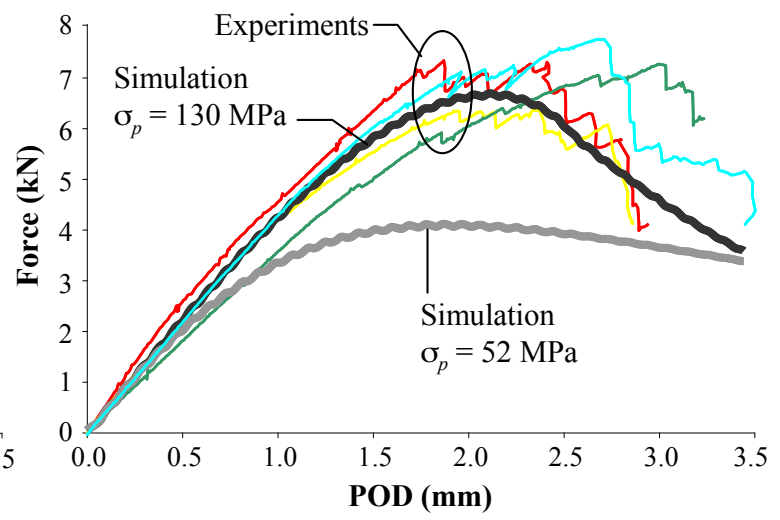

(b)

Fig. 9. Comparison between the numerically simulated and experimentally measured force vs. POD profiles for the: (a) 2-ply, and (b) 4-ply OCT specimens with axial tows oriented transverse to the loading direction. Also shown are the simulation results if peak strengths were extracted from standard coupon tensile tests $\left(\sigma_{p}=47\right.$ and $\left.52 \mathrm{MPa}\right)$.

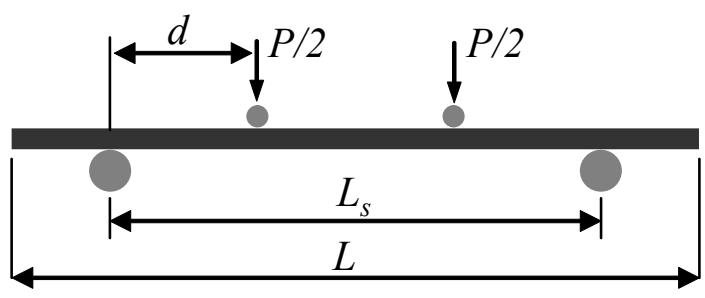

Fig. 10. Test configuration for four-point bend specimens. Lengths, $L=17.78 \mathrm{~cm}(7 \mathrm{in})$ and $22.86 \mathrm{~cm}$ (9 in) were tested. Other dimensions are listed in Table 1. 


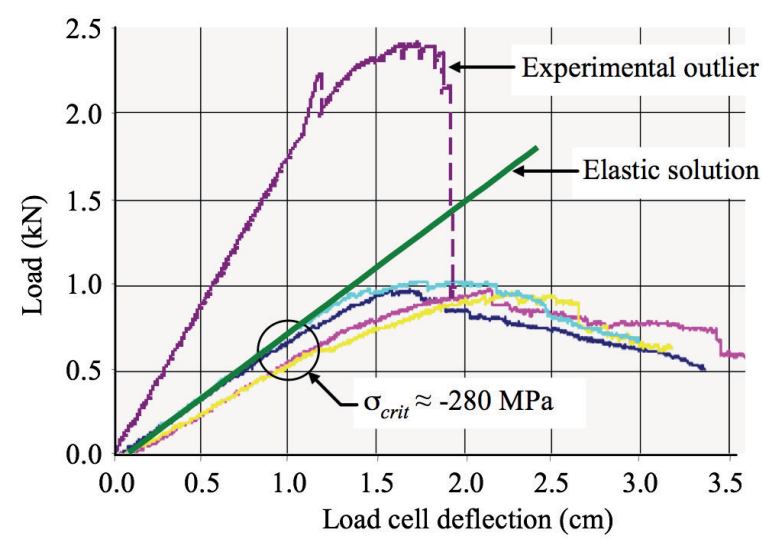

(a)

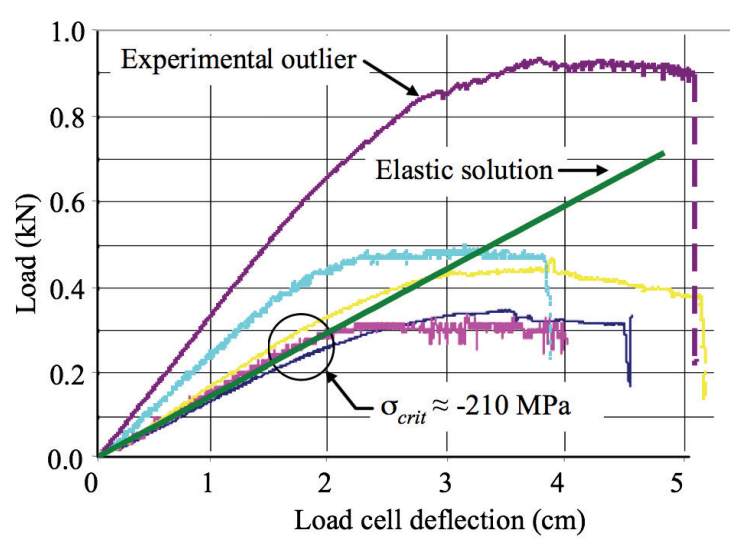

(b)

Fig. 11. Load versus machine displacement showing the divergence of the elastic solution from the experimental results [39] for: (a) $17.78 \mathrm{~cm} \mathrm{(7} \mathrm{in),} \mathrm{and} \mathrm{(b)} 22.86 \mathrm{~cm}$ (9 in) 4-point bend specimens at an outer fibre compressive stress of between -210 and -280 MPa. The region where the deviation from the elastic solution occurs is indicative of damage initiation and allows the critical value of the longitudinal compressive stress to be estimated.

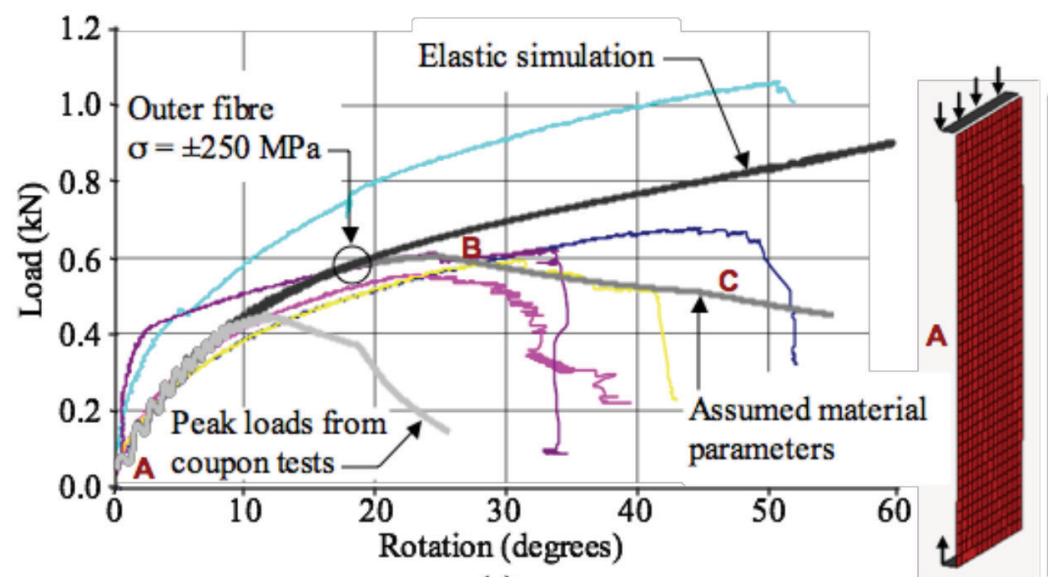

(a)

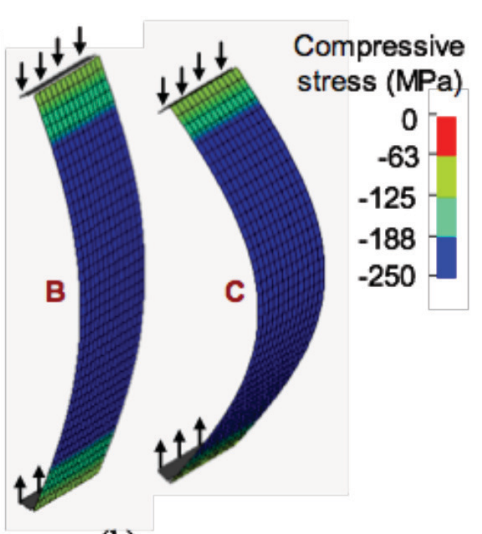

(b)

Fig. 12. (a) Comparison of simulation results (with three different assumptions with respect to material behaviour) to the experimental curves for the eccentric compression test on the 17.78 cm (7 in) specimen with $7 \mathrm{~mm}$ of eccentricity and (b) deformation behaviour corresponding to locations $\mathrm{A}, \mathrm{B}$, and $\mathrm{C}$ on the curve with the compressive strength equal to -250 MPa. Experimental results are taken from [39]. 

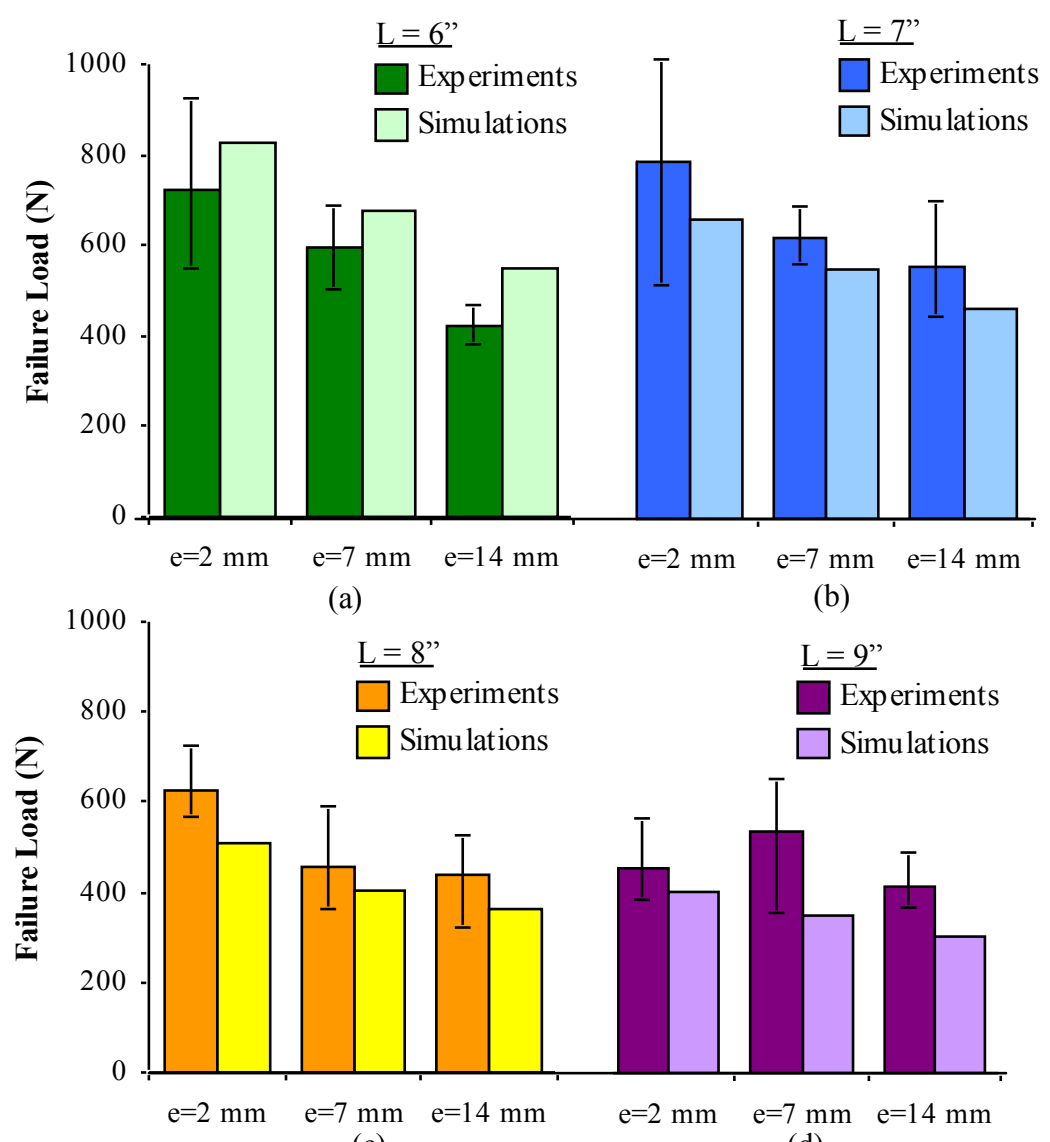

(c)

(d)

Fig. 13. Failure loads measured experimentally and predicted from simulations for the four lengths of eccentric-compression specimens tested under varying values of eccentricity, $e$. The experimental values [39] reported are the average, and the error bars represent the range of failure loads measured, excluding outliers. 


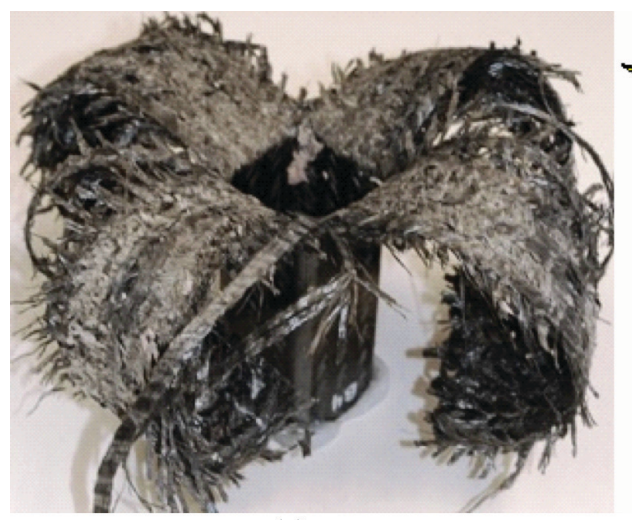

(a)

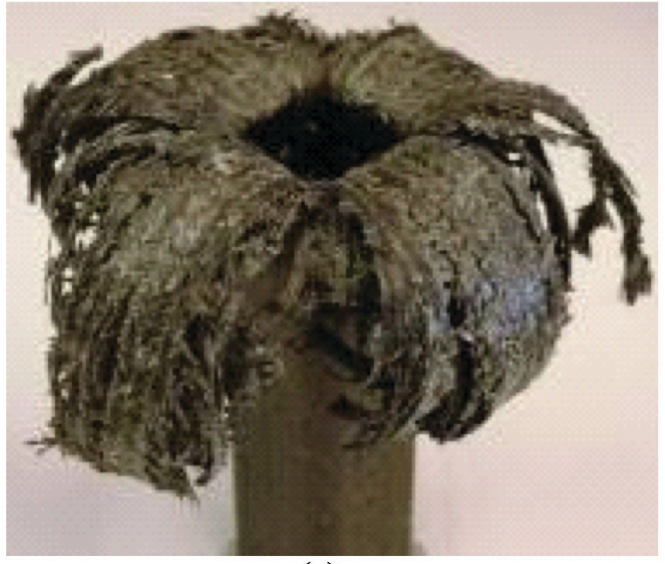

(c)

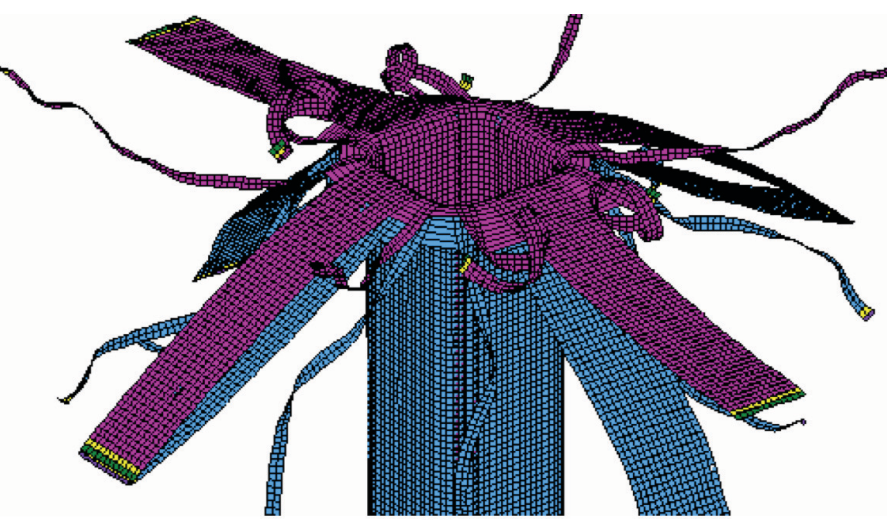

(b)

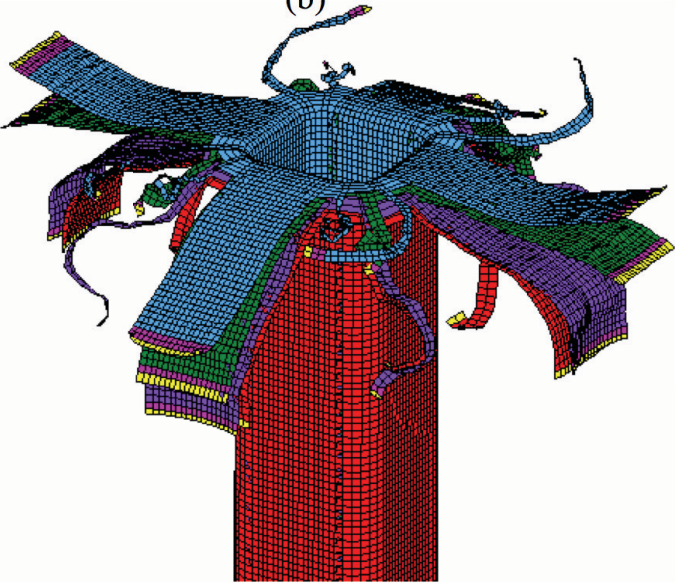

(d)

Fig. 14. Comparison of experimentally observed and predicted failure morphologies in 2-ply (a and b) and 4-ply (c and d) tubes crushed without plug initiator. Results from quarter-tube simulations have been mirrored to produce these images. 


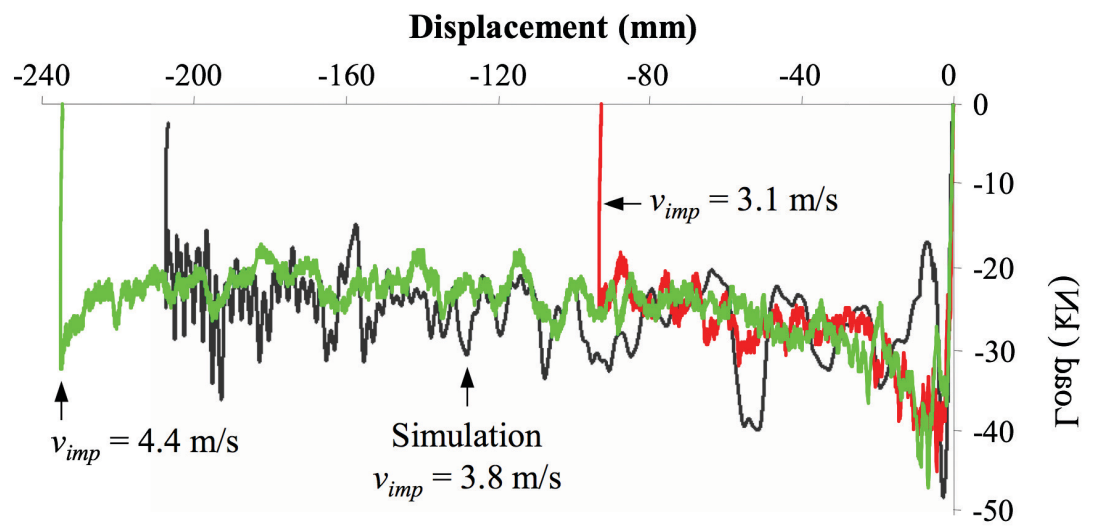

(a)

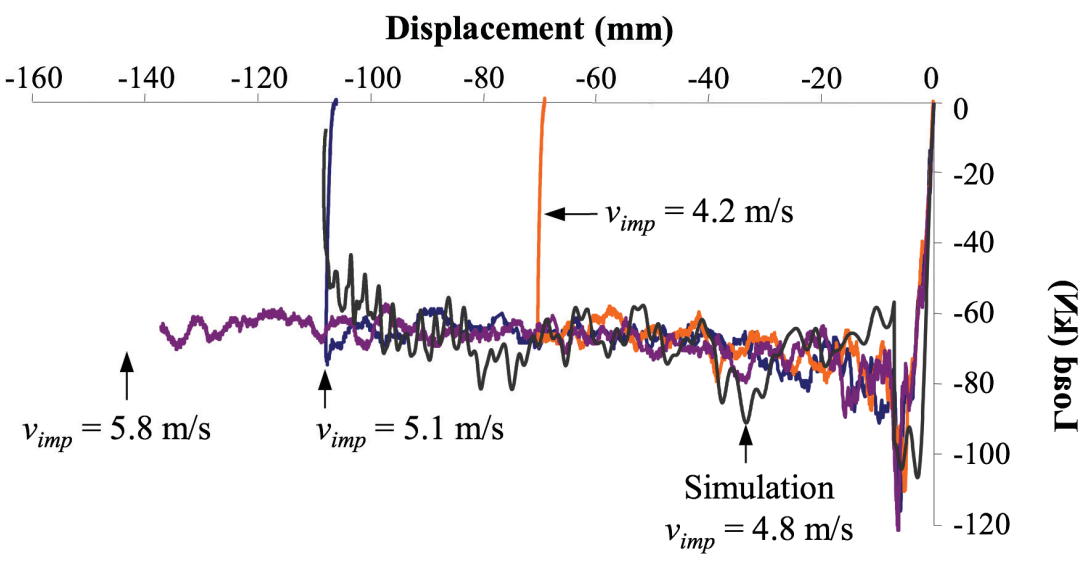

(b)

Fig. 15. Comparison of experimental and numerical force-displacement profiles for (a) 2-ply and (b) 4-ply tubes crushed without plug initiator. 

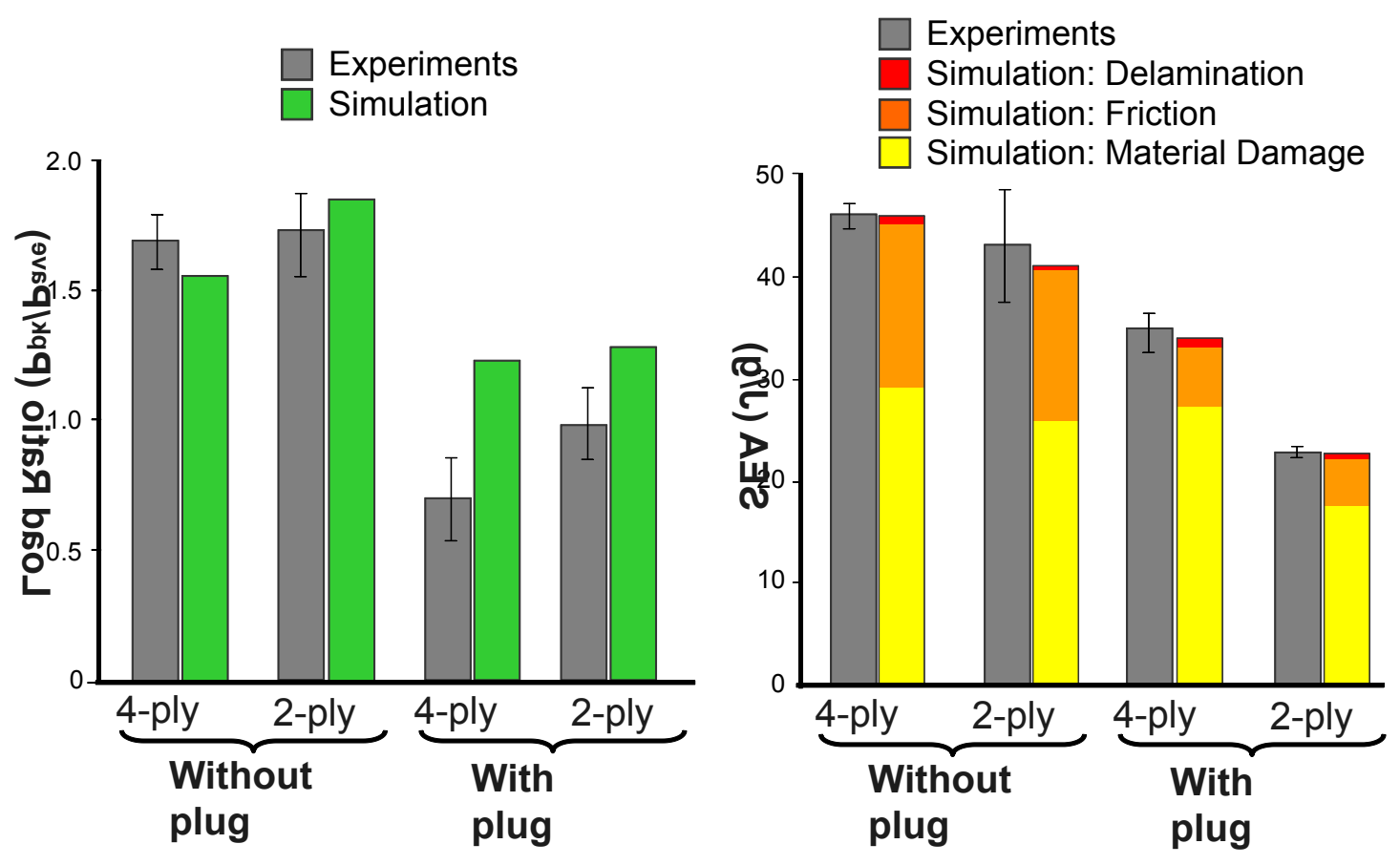

Fig. 16. Comparison of experimentally measured and numerically predicted values of load ratio and SEA obtained from crushing of braided composite tubes with and without plug initiator. 
Table 1 - Summary of four-point bend test results [39].

\begin{tabular}{llllll}
\hline $\begin{array}{l}\text { Specimen Length, } \\
L, \mathrm{~cm}(\mathrm{in})\end{array}$ & $d, \mathrm{~cm}$ (in) & $\begin{array}{l}L_{\mathrm{s}}, \mathrm{cm} \\
\text { (in) }\end{array}$ & $\begin{array}{l}\text { Average* } \\
\text { thickness }(\mathrm{mm})\end{array}$ & $\begin{array}{l}\text { Average* } \\
\text { width (mm) }\end{array}$ & $\begin{array}{l}\text { Average* Failure } \\
\text { Load, } P(\mathrm{~N})\end{array}$ \\
\hline $17.78(7)$ & $3.81(1.5)$ & $12.70(5)$ & 2.36 & 52.31 & 931 \\
$22.86(9)$ & $6.35(2.5)$ & $20.32(8)$ & 2.15 & 51.03 & 412 \\
\hline
\end{tabular}

* Average does not include outliers

Table 2 - Summary of model input parameters

\begin{tabular}{clccl}
\hline \multicolumn{1}{c}{ Mode } & \multicolumn{1}{c}{ Parameter } & 2-ply & 4-ply & \multicolumn{1}{c}{ Characterization/Calibration } \\
\hline Transverse Tension & Modulus, $E_{y}(\mathrm{GPa})$ & 12.5 & 13.75 & $\begin{array}{l}\text { Standard uniaxial tests [39] } \\
\text { adjusted using notched test } \\
\text { simulation }\end{array}$ \\
Transverse Tension & Peak stress, $\sigma_{p}(\mathrm{MPa})$ & 118 & 130 & $\begin{array}{l}\text { Over-height compact tension } \\
\text { test }(\mathrm{OCT}) \text { combined with FE } \\
\text { simulation }\end{array}$ \\
Transverse Tension & $\begin{array}{l}\text { Fracture energy, } G_{f}(\mathrm{~kJ} / \\
\left.\mathrm{m}^{2}\right)\end{array}$ & 47 & 55 & $\begin{array}{l}\text { Over-height compact tension } \\
\text { test (OCT) }\end{array}$ \\
Axial Compression & Modulus, $E_{x}(\mathrm{GPa})$ & 60 & 60 & $\begin{array}{l}\text { Standard uniaxial tests [39] } \\
\text { Axial Compression }\end{array}$ \\
$\begin{array}{l}\text { Plateau stress, } \sigma_{\text {crit }}= \\
\text { Peak Stress (MPa) }\end{array}$ & 250 & 250 & $\begin{array}{l}\text { Four-point bending test and } \\
\text { eccentric compression test [39] } \\
\text { combined with FE simulation }\end{array}$ \\
Interfacial Friction & $\begin{array}{l}\text { Friction coefficient used } \\
\text { in LS-DYNA contact } \\
\text { definitions }\end{array}$ & $0.22-$ & $0.22-$ & $\begin{array}{l}\text { Friction tests on similar } \\
\text { braided material [45] }\end{array}$ \\
Delamination & $\begin{array}{l}\text { Fracture energy, } G_{I c}(\mathrm{~kJ} / \\
\left.\mathrm{m}^{2}\right)\end{array}$ & 1.7 & 1.7 & $\begin{array}{l}\text { Double cantilever beam } \\
\text { (DCB) [43] tests }\end{array}$
\end{tabular}

